\title{
Thematic and Frequency Analyses of Caregivers' Report on Communication-related Chief Complaints in Progressive Aphasia
}

\author{
Ka young Kimª, Byoung Seok Ye ${ }^{\mathrm{b}}$, JuHee Lee ${ }^{\mathrm{c}}$, HyangHee Kim ${ }^{\mathrm{a}, \mathrm{d}}$ \\ ${ }^{a}$ Graduate Program in Speech and Language Pathology, Yonsei University, Seoul, Korea \\ ${ }^{b}$ Department of Neurology, Yonsei University College of Medicine, Seoul, Korea \\ 'Nursing Research Institute, Yonsei University College of Nursing, Seoul, Korea \\ ${ }^{d}$ Department and Research Institute of Rehabilitation Medicine, Yonsei University College of Medicine, Seoul, Korea
}

\author{
Correspondence: HyangHee Kim, PhD, CCC-SLP \\ Graduate Program in Speech and Language, \\ Yonsei University College of Medicine, 11-12 \\ Yeondaedongmun-gil, Seodaemun-gu, Seoul \\ 03721, Korea \\ Tel: +82-2-2228-3900 \\ Fax: +82-2-2227-7984 \\ E-mail: h.kim@yonsei.ac.kr
}

Received: April 20, 2021

Revised: May 21, 2021

Accepted: May 21, 2021

This article is based on the Master's thesis of the first author.

This work was supported by the Ministry of Education of the Republic of Korea and the National Research Foundation of Korea (No. NRF2017S1A5A2A01025920)
Objectives: Progressive aphasia is a symptom that gradually appears and the caregivers are the ones who first notice the changes of patients' communication abilities. Therefore, it is necessary to identify and analyze the chief complaints (CCs) reported by caregivers in order to better manage communication problems. Methods: First, communication-related CCs of 44 patients (men:women $=19: 25$, mean age $=70.5 \pm 10.14$ ) with progressive aphasia were extracted from the electronic medical records (EMRs), and thematic analysis was performed using the NVivo 1.0 program. Consequently, a 45 -item interview questionnaire was developed based on the contents of the CCs. Second, a semi-structured interview using the questionnaire was conducted with 9 caregivers (men:women $=2: 7$, mean age $=56.5 \pm$ 12.82) of patients to verify the questionnaire, and additional thematic and frequency analyses of contents of the interview were performed. Results: Six main themes and 18 subthemes were extracted from the caregivers' interview. The 6 main themes included 'verbal expression,' 'verbal comprehension,' 'written expression,' 'written comprehension', 'calculation', and 'speech'. As for the subthemes, 'word,' 'sentence,' linguistic aspect', 'reading comprehension', 'money management' and 'articulation' were the most frequently reported problems. In addition, the most severely perceived main themes of CCs were 'verbal expression', 'verbal comprehension', 'written comprehension' and 'speech'. Conclusion: CCs contain crucial information regarding the current status of communication abilities of patients with progressive aphasia. The results of this study may provide information for clinicians and patients/caregivers to understand the nature of communication problems among patients and to direct future planning of the intervention program.

Keywords: Progressive aphasia, Dementia, Communication-related chief complaints (CCs), Thematic analysis, Frequency analysis, Caregiver's questionnaire
진행성 실어증(progressive aphasia)은 뇌졸중과 같은 병인으로 발생하는 언어장애와는 달리 서서히 나타나는 증상으로서(Henry, Beeson, \& Rapcsak, 2008), 단독적으로 발현되거나 다른 인지장애 를 수반한다. 그런데 발병 후 최소 2 년간 인지장애를 동반하지 않고 언어장애만 독립적으로 나타나는 신경퇴행성 질환을 원발진행실 어증(primary progressive aphasia, $\mathrm{PPA}$ )이라고 한다(Gorno-Tem- pini et al., 2004). PPA는 진단된 후 말 또는 언어 증상에 따라 비유 창원발진행실어증(non-fluent variant $\mathrm{PPA}, \mathrm{nfvPPA})$, 의미변이원 발진행실어증(semantic variant PPA, svPPA), 로고페닉원발진행실 어증(logopenic variant PPA, lvPPA)이라는 세 가지 유형으로 분류 된다(Gorno-Tempini et al., 2011). nfvPPA는 실문법증(agrammatism)과 노력성 발화(effortful speech)가 특징적이며, svPPA는 대면 
이름대기 능력 손상 및 단단어 이해 저하가 핵심 특징으로 나타난 다. $\operatorname{lvPPA}$ 는 단어 인출 장애를 보이고, 문장 산출 능력이 저하된다. $\mathrm{PPA}$ 와 같이 인지장애를 동반하지 않는 진행성 실어증이라 할지라 도 병기가 진행됨에 따라 인지 저하를 동반하는 상태로 발전하기 도 한다(Harciarek, Sitek, \& Kertesz, 2014; Mesulam, 1990).

이러한 진행성 실어증을 유발하는 원인 질환으로는 알츠하이머 병(Alzheimer's disease, $\mathrm{AD}$ ), 루이소체 치매(Lewy body dementia, $\mathrm{LBD})$, 전두측두치매(frontotemporal dementia, FTD) 등이 있다 (Olney, Spina, \& Miller, 2017; Petrova et al., 2016). 그 기저 원인 질 환에 따라 언어 증상이 상이하며, 앞서 기술된 서로 다른 유형의 진 행실어증을 보일 수 있다. $\mathrm{AD}$ 에서는 정상 노년층에 비해 이름대기 수행이 저하되며(Klimova, Maresova, Valis, Hort, \& Kuca, 2015), 에둘러말하기(circumlocution)와 대명사 사용이 빈번하게 나타난 다. $\mathrm{AD}$ 는 병기가 진행될수록 대화 상대방의 말에 적절하게 반응하 거나 자신의 생각을 표현하는 데에도 어려움을 보인다(Klimova et al., 2015). LBD는 매우 경미한 단계부터 이름대기에서 수행 저하가 관찰된다(Petrova et al., 2016). FTD의 아형인 svPPA와 nfvPPA에서 는 단어 인출 장애 등의 언어 문제가 초기부터 나타난다(Olney et al., 2017).

이러한 언어 문제들은 전반적인 의사소통능력을 저하시키는데, 의사소통능력은 건강관리 질이나, 삶의 질(quality of life)과 밀접하 게 관련되어 있기 때문에(Hilari \& Byng, 2009; Johnson \& Lin, 2014), 언어 증상에 대한 정확한 파악이 필수적이다. 그런데 진행성 실어증 환자들이 의료진과의 초진 면담 동안 본인의 언어 증상에 대해 정확한 기술이 어려우며 의료진 또한 짧은 진료 시간 내에 언 어 증상에 대한 체계적인 면담이 수월하지 않다. 특히 대부분 진행 성 실어증의 초기 증상으로 이름대기 장애가 나타나며(Croot et al., 2019), 병이 진전된다고 하더라도 서로 다른 유형의 증상이나 징후 가 중첩된다(Nuvoli, Tanda, Stazza, Madeddu, \& Spanu, 2019). 이 로 인해 진행성 실어증에 대한 임상적 진단과 아형 분류의 어려움 이 발생함으로써, 진행성 실어증을 진단하고 유형을 감별할 수 있 는 방안을 강구할 필요성이 대두된다.

언어능력을 평가하는 방법으로는 임상가가 환자에게 평가도구 등을 활용하여 검사를 직접 실시하는 '직접 평가'와 환자 본인이나 보호자에게 증상에 대해 보고하게 하는 '간접 평가'가 있다. 환자 및 보호자가 보고하는 주호소(chief complaints, CCs)는 병으로의 진전 가능성을 예측하기 위해서 증상을 감시하는 데 사용된다 (Wang et al., 2017). 따라서 환자 및 보호자가 느끼는 주관적 증상 에 대해 응답하는 '간접 평가'가 유용할 수 있으며, 주관적인 증상 을 분석하는 것이 병의 진전을 예측하여 조기 선별하고 더 나아가
예후를 확인하는 데 중요한 역할을 할 수 있다.

'간접 평가'는 주로 설문을 통해 이루어지는데, 개방형(openended) 질문과 폐쇄형(close-ended) 질문을 함께 제공하여 환자와 보호자가 느끼는 증상에 대해 정보를 제공하게 할 수 있다. 이때, 개 방형 질문은 인터뷰 형식을 활용하여 질문지에는 없지만 증상에 대해서 자세하게 설명할 수 있으며, 평가 척도(rating scale)를 사용 하는 폐쇄형 질문은 증상의 정도를 수량화할 수 있다는 장점이 있 다(Chen, Baker, \& Lam, 2020; Jones \& Tanner, 2015).

한편, 인터뷰를 거쳐 환자나 보호자가 보고하는 주관적인 증상 에 대한 분석은 '주제 분석(thematic analysis)'을 통해 체계적으로 가능하다(Kim, Kim, Nam, \& Kim, 2020). 주제 분석은 수집한 자 료의 주제 패턴을 확인하고, 분석하여 보고하는 방법이다(Nowell, Norris, White, \& Moules, 2017). '주제(theme)'는 전체 자료 내에서 반복되어 나타나는 특성으로서 전체 발화의 대표성을 가진다(Kim et al., 2020). 따라서 주제 분석을 통해 진행성 실어증에게서 공통적 으로 나타나는 언어 특성을 확인할 수 있다.

본 연구의 목적은 다음의 두 가지이다. 첫째, 전자의무기록(Electronic Medical Record, EMR)에서 보고된 진행성 실어증 환자의 언어능력 관련 주호소를 주제 분석하여 설문지를 제작한다. 둘째, 제작된 설문지를 바탕으로 보호자 인터뷰를 통해 진행성 실어증 환자들의 언어능력에 대한 주호소를 재확인한다. 이를 위하여, 인 터뷰 내용을 주제 분석하여 상위 주제 및 하위 주제와 주제별 빈도 를 도출하고, 진행성 실어증 환자들의 언어장애 증상 정도를 파악 한다.

\section{연구방법}

\section{연구대상}

본 연구는 두 단계에 걸쳐 연구 대상을 선정하고 자료를 수집하 였다. 첫째, 2019년 1월부터 2020년 4월까지 서울 소재 대학병원 신 경과 외래에 내원하여 언어 검사가 의뢰된 진행성 실어증 환자 44 명을 대상으로 하였으며, 진행성 실어증의 평가와 진단은 신경과 전문의(B.Y.)와 신경언어장애 전공 교수(H.K)에 의해 이루어졌다. 진행성 실어증 환자는 병력 청취 상에서 언어기능 장애에 대한 호 소가 있거나, 한국판 보스톤 이름대기 검사(Korean version-Boston Naming Test, K-BNT; Kim \& Na, 1997) 결과에서 1.5 SD 이하 의 수행을 보인 사람으로 한정하였다. 대상자 44 명(남자:여자=19:25) 의 성별, 연령, 교육년수, 한국판 간이정신상태검사(Korean-Mini Mental State Examination, K-MMSE; Kang, Na, \& Hahn, 1997) 점 수에 대한 기초 임상 정보는 Table 1 과 같다. 평균 연령은 70.5 
( \pm 10.14$)$ 세, 평균 교육년수는 11.0 ( \pm 5.62$)$ 년, 평균 K-MMSE 점수 는 20.2 ( \pm 6.49$)$ 점이었다.

둘째, 설문을 개발한 후에 주호소 내용을 재확인하기 위하여 서 울 소재 대학병원 신경과 외래에서 언어검사가 의뢰된 진행성 실어 증 환자의 주 보호자 9명을 대상으로 설문지를 바탕으로 한 심층 인터뷰를 실시하였다. 보호자 인터뷰는 2020년 7월 10 일부터 10 월 29 일까지 약 3 개월간 진행되었다. 진행성 실어증 환자 선정 기준은 $\mathrm{EMR}$ 조사와 동일하다. 환자 9명(남자:여자 $=5: 4)$ 의 성별, 연령, 교 육년수, K-MMSE 점수, 진단명 및 보호자 성별, 연령, 환자와의 관

Table 1. Demographic information of patients with progressive aphasia

\begin{tabular}{lc}
\hline Variables & Values \\
\hline Age (yr) & $70.5(10.14)$ \\
Sex (N) & \\
Male & 19 \\
Female & 25 \\
Education (yr) & $11.0(5.62)$ \\
K-MMSE & $20.2(6.49)$ \\
\hline
\end{tabular}

Values are presented as mean (SD).

K-MMSE=Korean-Mini Mental State Examination (perfect score: 30); yr=year; $\mathrm{N}=$ number.
계에 대한 기초 임상 정보는 Table 2와 같다. 환자들의 평균 연령은 72.8 ( \pm 7.96 )세, 평균 교육년수는 13.5 ( \pm 5.18 )년, 평균 K-MMSE 점수는 22.1 ( \pm 8.13$)$ 점이었다. 환자들의 진행성 실어증의 유형은 $\operatorname{lvPPA} 4$ 명, svPPA 3명, nfvPPA 2명으로 분류되었다. 환자의 보호자

Table 2. Demographic information of patients and their caregivers

\begin{tabular}{|c|c|c|c|c|c|c|}
\hline No. & $\begin{array}{c}\text { Age (yr)/ } \\
\text { Sex }\end{array}$ & $\begin{array}{c}\text { Education } \\
\text { (yr) }\end{array}$ & K-MMSE & Dx. & $\begin{array}{c}\text { Caregivers' } \\
\text { Age (yr)/Sex }\end{array}$ & $\begin{array}{l}\text { Relation- } \\
\text { ship with } \\
\text { patients }\end{array}$ \\
\hline 1 & $76 / M$ & 16 & 27 & IVPPA & $75 / F$ & Spouse \\
\hline 2 & $67 / M$ & 6 & 24 & IVPPA & $63 / F$ & Spouse \\
\hline 3 & $80 / F$ & 18 & 28 & IVPPA & $54 / F$ & Daughter \\
\hline 4 & $83 / \mathrm{M}$ & 12 & 1 & IvPPA & $58 / M$ & Son \\
\hline 5 & 73/M & 18 & 25 & svPPA & $34 / F$ & Daughter \\
\hline 6 & $83 / F$ & 18 & 22 & svPPA & $53 / F$ & Daughter \\
\hline 7 & $63 / F$ & 18 & 24 & svPPA & $66 / M$ & Spouse \\
\hline 8 & $66 / F$ & 6 & 23 & nfvPPA & $41 / \mathrm{F}$ & Daughter \\
\hline 9 & $65 / M$ & 10 & 25 & nfvPPA & $65 / F$ & Spouse \\
\hline Mean (SD) & $72.8(7.96)$ & $13.5(5.18)$ & $22.1(8.13)$ & & $56.5(12.82)$ & \\
\hline
\end{tabular}

K-MMSE=Korean-Mini Mental State Examination (perfect score: 30); yr=year; $\mathrm{Dx}=$ Diagnosis of language variants; $\mathrm{SD}=$ Standard deviation; IvPPA= logopenic variant PPA; svPPA = semantic variant primary progressive aphasia; nfvPPA = nonfluent variant primary progressive aphasia.

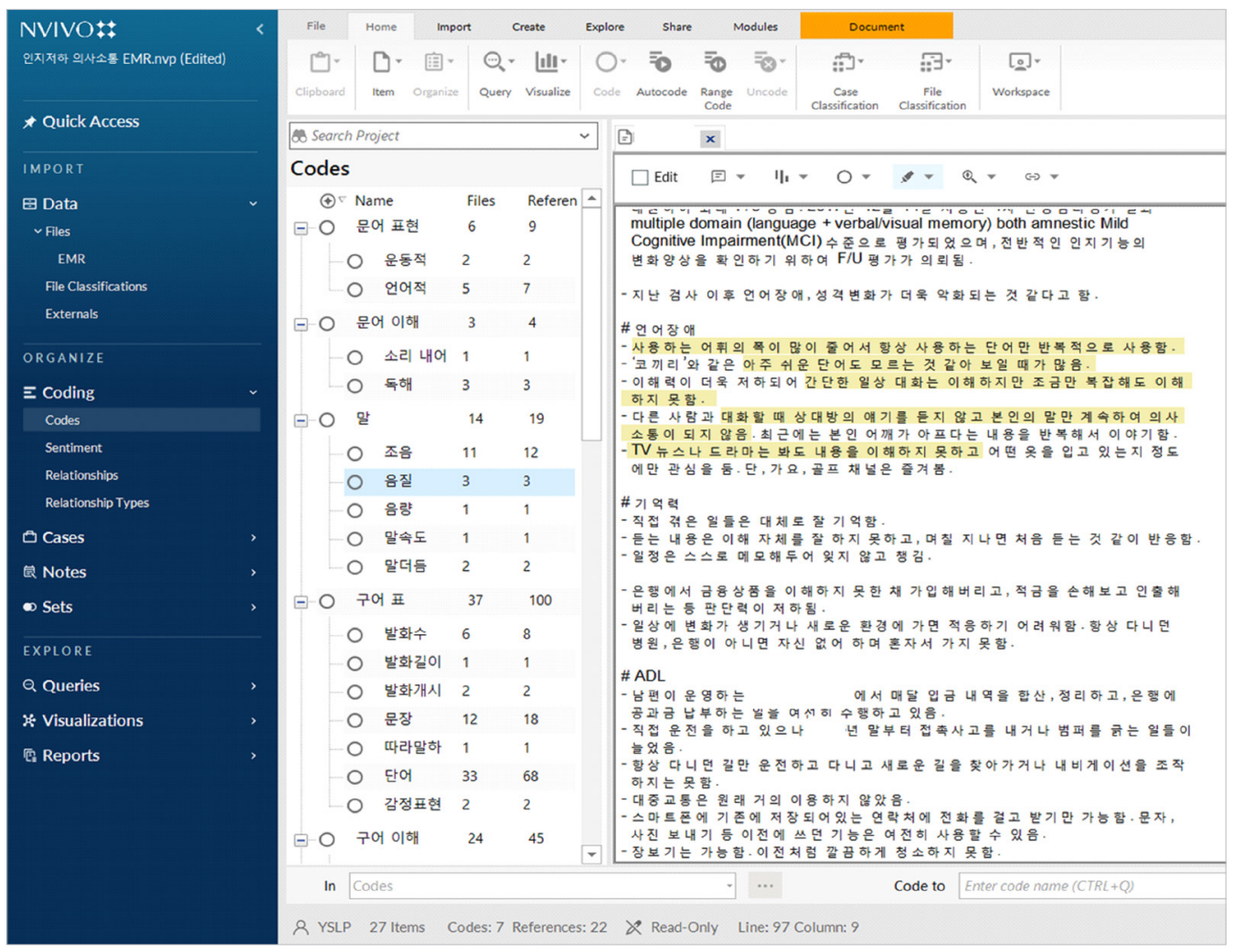

Figure 1. Screen example of data coding using the NVivo 1.0. 
는 (1) 신경학적 질환이 없으며, (2) 인지장애 및 정신적 질환으로 인 한 문제가 없고, (3) 연구자와의 질의 문답이 가능하며, (4) 주 3회 이 상 환자를 돌본다고 보고한 주 보호자이다. 보호자는 남자 2 명, 여 자 7명이었으며, 평균 연령은 $56.5( \pm 12.82)$ 세였다. 환자와의 관계 는 배우자 4 명, 자녀 5 명이었다.

\section{연구절차}

연구를 진행하기 앞서, 신촌 세브란스병원 연구심의위원회(Institutional Review Board, IRB) (과제번호: 4-2020-0920)의 승인을 받았으며, 보호자는 설문 조사 전에 사전 동의서를 작성하였다. 총 두 단계에 걸친 연구 절차는 다음과 같다. 첫 단계에서는, 각 연구 대상자의 $\mathrm{EMR}$ 에서 보고된 주호소에서 언어 관련 내용을 정리한 후 '주제 분석'을 실시하였다. 자료 분석 절차는 다음과 같다. 먼저 EMR 내용을 텍스트 파일로 전사하였다. NVivo 1.0 프로그램에서 텍스트 파일을 불러온 뒤, 전사된 내용이 환자의 언어와 관련된 발 화인지를 확인하고, 주제와 관련된 발화인 경우 각 주제별로 코딩 하였다(Figure 1). 코딩된 코드를 바탕으로 상위 주제(main themes) 와 하위 주제(subthemes), 그리고 각 주제의 빈도를 도출하였으며, 이를 바탕으로 언어 설문지를 제작하였다.

두 번째 연구 단계에서는 환자의 언어능력을 심층적으로 파악하 기 위하여, 개발된 ‘언어 설문지’를 제공하여 '반구조화된' 인터뷰 를 진행하였다. 폐쇄형 질문은 설문 문항에 대해 Likert 5 점 척도로 응답하게 하였다. 이전과 비교한 현재 환자의 수행을 파악하기 위 해, 현재 관찰되는 문제라고 하더라도 이전에도 동일한 문제가 관 찰되었다면 '전혀 그렇지 않다' 또는 '그렇지 않다'로 기록하게 하였 다. 환자의 언어능력에 대한 추가적인 정보를 확인하기 위하여 개방 형 질문을 제공하였다. 인터뷰 내용은 추후 주제 분석을 위해 모두 녹음되었다. 녹음된 보호자 인터뷰를 듣고 텍스트 파일로 전사하 였다. 이후 분석 절차는 EMR 조사 시 사용한 방법과 동일하다. 분 석은 질적 자료 분석 소프트웨어인 NVivo 1.0 프로그램(https:// www.qsrinternational.com/nvivo-qualitative-data-analysis-software/home)을 사용하였다.

\section{통계분석}

주호소의 각 문항별 비교를 위하여, SPSS Statistics 25 (Statistical Package for the Social Sciences version 25)를 사용하여 각 설문 문 항의 중위수를 산출하였다. 단, 보호자가 관찰한 적이 없다고 한 문 항은 제외하였다.

\section{연구결과}

\section{제1단계: 설문지 제작}

$\mathrm{EMR}$ 에서 보고된 진행성 실어증 환자의 언어능력을 주제 분석 한 결과, 총 6 개의 상위 주제와 총 21 개의 하위 주제가 도출되었다. 상위 주제는 '구어 표현(verbal expression)', '구어 이해(verbal comprehension), '문어 표현(written expression)', '문어 이해(written comprehension)', '계산(calculation)', '말(speech)'이었다. 도출된 상위 주제 및 하위 주제와 주제 발화 빈도는 Table 3에 제시하였다. 상위 주제 및 하위 주제를 바탕으로 총 45 문항의 '언어 설문지'를 제작하였으며, 각 주제별 문항은 언어 관련 주호소를 활용하였다. '구어 표현' 영역은 총 22개 문항으로 정리되었으며, '구어 이해' 영 역은 9개 문항을 선정하였다. '문어 표현'과 ‘문어 이해'는 각 3 개의 문항을 포함하였으며, '계산’은 1개 문항으로, '말'은 7개 문항으로 정리되었다. 제작된 설문지는 Appendix 1과 같다.

\section{구어 표현}

$\mathrm{EMR}$ 조사 시 진행성 실어증 환자들에게서 가장 많이 나타난 언 어 문제는 ‘구어 표현'과 관련된 어려움이었다. 구어 표현과 관련된 하위 주제는 7개로서 '단어', '문장', '발화 수', '발화 개시', '감정 표

Table 3. Utterance frequency of main themes and subthemes in EMRs

\begin{tabular}{ll}
\hline Main themes (reported frequency) & \multicolumn{1}{c}{ Subthemes (reported frequency) } \\
\hline Verbal expression (100) & Word (68) \\
& Sentence (18) \\
& Number of utterance (8) \\
& Initiation of utterance (2) \\
& Emotional expression (2) \\
& Length of utterance (1) \\
& Repetition (1) \\
& Utterance (23) \\
& Sentence (15) \\
Verbal comprehension (45) & Word (7) \\
& Articulation (12) \\
& Voice quality (3) \\
Speech (19) & Stuttering (2) \\
& Speech rate (1) \\
& Loudness (1) \\
& Linguistic aspect (7) \\
Motoric aspect (2) \\
Written expression (9) & Money management (3) \\
Calculation (5) & Four fundamental arithmetic operations (2) \\
Written comprehension (5) & Reading comprehension (3) \\
& Reading aloud (2) \\
\hline
\end{tabular}

EMR=Electronic Medical Record. 
현, '발화 길이, ‘따라말하기’ 빈도 순이었다. ‘단어'와 관련된 문제 로서 가장 많이 보고한 내용은 "물건의 이름이 떠오르지 않는다" 이었으며, “사람 이름을 잘 떠올리지 못한다”도 많이 보고하였다. 또한 "이름을 엉뚱하게 말할 때가 있다", "단어를 틀리게 말한다" 와 같이 착어(paraphasia) 문제를 언급하였다. '문장' 산출과 관련 하여 "대화할 때 본인이 하고 싶은 말만 한다", "본인의 의견을 조 리 있게 정리하여 표현하지 못한다”고 하였다. '발화 수’ 관련 어려 움으로는 발화 수 감소가 두드러졌는데 보호자들은 환자들의 "말 수가 줄었다”고 보고하였다. 환자들은 ‘발화 개시’ 문제, 즉 자발적 으로 말을 시작하는 데 어려움이 있었다. 또한, '감정 표현' 문제가 보고된 환자들은 ‘무표정한 얼굴’ 또는 ‘우울감’을 동반하였다. '발 화 길이'에서 환자들은 길게 말을 하지 않고, "단어만으로 의사소 통을 한다"고 보고하였다. 환자는 대화 상대방의 말을 그대로 따라 하는 특성을 보였는데, 이는 '반향어(echolalia)'로 특색 지어질 수 있다.

\section{구어 이해}

두 번째로 많이 보고된 언어 문제는 '구어 이해' 능력의 저하이 다. 하위 주제는 '단어', '문장', ‘담화’로 도출되었다. 진행성 실어증 환자들은 '담화' 이해에 가장 어려움을 보였다. 가장 많이 보고된 문제는 “텔레비전 내용을 이해하지 못한다”이었으며, 보호자들은 "텔레비전을 멍하니 보고 있는 것 같다", "이해가 안 되는 프로그램 은 시청하지 않고 채널을 돌린다" 등을 보고하였다. "대화 내용을 이해하지 못한다”도 많이 언급된 문제로, 특히 “전화로 들은 내용 을 더 이해하지 못하는 것 같다”고 하였다. 환자들은 보다 짧은 문 장을 이해하는 데에도 어려움이 있었다. 가장 많이 언급된 문제는 “말을 이해하는 속도가 느려졌다"이었으며, 이로 인하여 질문에 답 을 늦게 하거나 여러 번 다시 말해주어야 한다고 보고하였다. 그 밖 에도 "말을 잘 이해하지 못하고 되묻는다", "질문과는 다른 대답을 한다” 등이 자주 언급되었다. 또한 보호자들은 환자들이 담화나 문장뿐만 아니라 “단어를 잘 이해하지 못하는 것 같다"고 하였다.

\section{말}

세 번째로 많이 보고된 언어 문제는 '말’ 문제로, ‘조음, ‘음량', ‘음 질, '말속도', '말더듬' 다섯 가지 하위 주제가 도출되었다. 가장 많이 언급된 조음 문제는 '왜곡(distortion)'이었는데, 말이 '어눌하다', '어둔하다', '부정확하다', '불분명하다라고 표현하였다. 두 번째로 많이 보고된 말 문제는 ‘음질’로서, '쉰 목소리'와 ‘힘겨운 발성’이 언 급되었다. "말더듬과 관련하여 “말더듬이 있다”고 보고하였으며, 말속도 저하와음량 감소가 있다는 의견이 있었다.

\section{문어 표현}

진행성 실어증 환자들은 쓰기에서도 저하된 수행을 보였다. 쓰기 는 중추형인 '언어적(linguistic) 측면'의 문제와 말초형인 '운동적 (motoric) 측면'의 문제 두 가지 하위 주제로 도출되었다. 언어적 측 면의 문제는 중추신경계의 손상에 기인한 것으로, 주로 맞춤법과 관련된 오류를 보고하였다. 보호자들은 “철자를 틀린다”, "오타가 심한 문자를 보낸다"고 언급하였다. 또한, 말초신경계의 손상에 의 한 운동적 문제도 나타났는데, 글씨체 변화로서 "글씨를 흘려 쓴 다"고보고하였다.

\section{계산}

계산은 '사칙연산'과 ‘돈 계산' 두 가지 하위 주제로 도출되었다. '돈 계산' 측면에서는, "돈 계산을 할 때 시간이 오래 걸린다", "금전 관리를 남에게 맡긴다", "중요한 돈 관리를 맡기기에는 불안하다" 고 하였다. 사칙연산은 비교적 쉬운 계산능력을 요하는 과제로, 많 이 보고되지는 않았으나 "많은 양을 계산해야 할 때 오류를 보인 다", “틀리지는 않지만 계산하는 시간이 오래 걸린다”는 의견이 있 었다.

\section{문어 이해}

문어 이해 측면에서는 '독해'와 '소리 내어 읽기' 두 가지 하위 주 제가 도출되었다. '독해” 측면에서 "읽기는 가능하지만 이해하지는 못한다" "복잡한 글을 이해하지 못하는 것 같다"고 하였다. 또한, '소리 내어 읽기'와 관련하여 “글자를 빠뜨리고 읽을 때가 있다”고 하였다.

\section{제2단계: 보호자 인터뷰}

\section{보호자 인터뷰 주제}

보호자 인터뷰 내용을 주제 분석한 결과, 총 6 개의 상위 주제와 18 개의 하위 주제가 도출되었다. 상위 주제는 EMR 조사주제 분석 결과와 동일하였으나, 하위 주제는 '따라말하기', ‘음질', ‘소리 내어 읽기'가 보고되지 않았다. 도출된 상위 주제 및 하위 주제와 주제 발화 빈도는 Table 4 와같다.

구어표현

EMR 조사 결과와 동일하게 진행성 실어증 환자들에게 가장 많 이 나타난 언어 문제는 '구어 표현'과 관련된 어려움이었다. 구어 표 현과 관련된 하위 주제는 6개로서, '단어', '문장', '발화 개시', '발화 길이', '발화 수, '감정 표현' 빈도 순이었다. 하위 주제의 빈도에 따 라 나타난 워드 클라우드는 Figure 2와 같다. 
Table 4. Utterance frequency of 6 main themes and 18 subthemes

\begin{tabular}{ll}
\hline Main themes (reported frequency) & \multicolumn{1}{c}{ Subthemes (reported frequency) } \\
\hline Verbal expression (76) & Word (24) \\
& Sentence (22) \\
& Initiation of utterance (12) \\
& Length of utterance (10) \\
& Number of utterance (7) \\
& Emotional expression (1) \\
& Sentence (16) \\
& Utterance (13) \\
Verbal comprehension (35) & Word (6) \\
& Articulation (9) \\
& Speech rate (5) \\
Speech (18) & Stuttering (3) \\
& Loudness (1) \\
Linguistic aspect (8) \\
Written expression (11) & Motoric aspect (3) \\
Calculation (5) & Money management (4) \\
Written comprehension (3) & Four fundamental arithmetic operations (1) \\
\hline
\end{tabular}

단어

보호자들은 진행성 실어증 환자들이 단어를 인출하는 데 가장 어려움이 있다고 보고하면서 다음과 같이 표현하였다. "이거 뭐 지”, "이게 뭐야”라고 하는 등 상대방에게 단어의 이름에 대해 묻거 나, “난 잘 모르겠다”라고 말하며 회피하는 모습을 보인다고 하였 다. 그 밖에도 "생각은 나는데 입으로 나오지 않는 것 같아요", "단 어를 에둘러서 표현해요"라고 하였다. "단어를 엉뚱하게 말해요", “단어 발음을 잘못해요" 등착어 문제도 자주 언급되었다.

(a) 발화는 '약사를 '약 파는 애'로 대치한 것을 통해 단어 인출의 어려움으로 인하여 에둘러말하기가 나타난 것을 확인할 수 있다. (b) 발화는 사람의 이름을 떠올리지 못하는 문제를 언급한 예시이다.

(a) "약을 어디서 받아온 거야? 그랬을 때 내가 어떤 질병이 있어서 약국에 가니까 약 파는 애가 이걸 쓰라고 하더라 고 이런 식으로."

(b) "손주 이름도 까먹고. 아들의 자식과 딸의 자식을 바꿔서 말해요 이름을."

문장

두 번째로 많이 나타난 하위 주제는 '문장' 수준의 말하기였다. 보호자는 진행성 실어증 환자들이 "주제에서 벗어난 말을 해요", "앞뒤가 다른 말을 해요", "말을 횡설수설해요”와 같이 주제 유지에 어려움이 있다고 하였다(a). 그 밖에도 "본인이 하고 싶은 말만 해

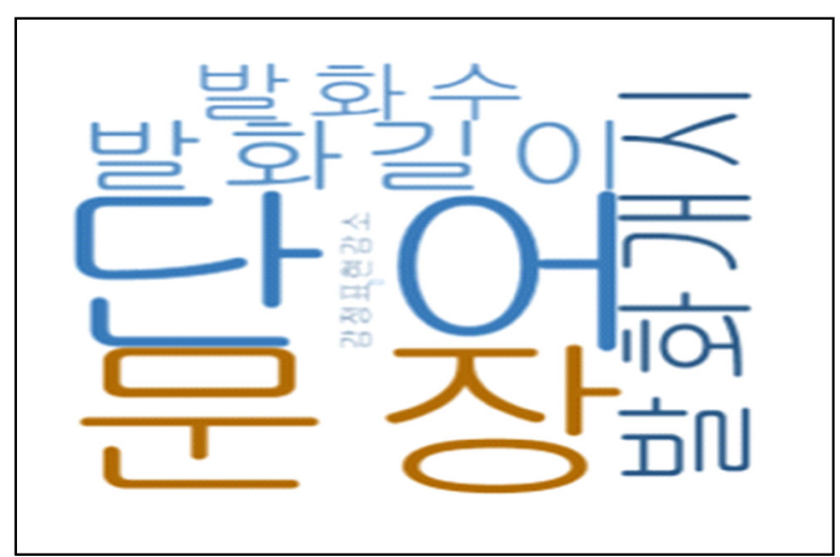

Figure 2. A word cloud of subtheme in 'verbal expression'.

요"와같이 대화차례지키기(turn-taking)의 문제도 언급되었다(b).

(a) "평소에는 이런 반대되는 말을 해요. '지금 여기가 어디입 니까’라고 하면 '아침밥이다’ 이런 식으로.", “헛소리를 많 이 하는 거는 마음이 불안할 때 이럴 때는. 좀 횡설수설도 하는 거 같은데. 안 그러면 말을 잘 안 하고."

(b) "앞뒤 맥락 없이 본인이 하고 싶은 이야기만 해요."

\section{발화 개시}

진행성 실어증 환자들은 '발화 개시’에도 문제가 있었다. 보호자 들은 환자들이 “말을 거의 안 해요”라고 호소하였으며, 이를 “대화 내용을 이해하지 못해서'라고 보는 경우가 많았다(a). 또한 모임같 이 사람들과 많이 마주하는 장소에서 말을 하지 않는 것을 우려하 였다(b).

(a) "대화 내용도 이해하지 못해서 어디를 가든 말을 잘 안 해."

(b) "옛날에는 모임 가서 뭐 어땠냐 이런 걸 말하잖아요. 근 데 그게 없어. 안부 인사 정도 하면 하는데 사회적으로 어 떻고 골프가 어떻고 이런 애기 할 법한데 안 해요."

발화 길이

네 번째로 많이 언급된 문제는 '발화 길이’이었으며, “요점만 말 해요(a)", "짧은 말은 가능하지만 말을 길게 하면 연결이 되지 않는 것 같아요(b)"라고 보고하였다.

(a) "정말 많이 짧아졌어요. 집에서도 요점만 딱 맞다 아니다 이 정도로만 애기하지." 
(b) "집에서는 길게는 못하고 간단한 짧은 말은 바로. 길게 문장 이 연결 안 돼서긴 말은 잘 못해요."

발화수

“발화 수'와 관련하여 “말 수가 줄어들었어요", "말이 거의 없어 요”라고 하였으며, “말을 안 하고 행동으로 말해요”라고 보고하기 도하였다.

(a) "말을 안 하고 행동으로 말해요. 그럼 알아서 하는 거야. "뭐 말하는 거냐'고 뭐라고 하면은 바로 또 대꾸도 안 해요.”

감정 표현

감정 표현 감소도 보고되었는데, 이러한 문제가 보고된 환자는 감정의 변화가 적어진 것으로 나타났다. 따라서 무감정과 감정표현 의 감소가 동반되어 나타나는 특성임을 확인할 수 있었다.

\section{(a) “감정표현은 원래 많았는데 많이 줄었어요.”}

\section{구어이해}

진행성 실어증 환자들이 두 번째로 많이 보이는 언어 문제는 구 어 이해 능력의 저하였다. 하위 주제는 '단어', '문장', '담화'로 도출 되었다.

문장

진행성 실어증 환자들은 문장을 이해하는 데 가장 어려움을 느끼 는 것으로 확인되었다. 가장 많이 언급된 문제는 "말을 이해하는 속 도가 느려졌어요(a)"이었으며, 그 밖에도 “여러 번 반복해서 말해야 이해해요" "말을 이해하지 못하고 되물어요(b)" 등을 보고하였다.

(a) “제가 하는 말을 못 알아들으시고 다시 애기하면 '아 그거' 이 러는 건 있어요. 이해하는 속도는 많이 느려진 거 같아요."

(b) “이해를 못하니까 대답을 안 해. '이걸 반으로 접어요' 이러면 이해를 못하니까 한참 있고 멋대로 접어. 이해를 못하니까. 말 을 이해하지 못하고 되묻는 경우도 많아요."

담화

담화 수준에서도 이해하는 데 어려움이 있다고 보고하였다. "대 화 내용을 이해하지 못하는 것 같아요(a)", "텔레비전 내용을 이해 하지 못하는 것 같아요(b)"가 가장 많이 언급된 문제였으며, 두 가 지 문제가 함께 나타나는 경우도 있었다. 환자들의 담화 이해 능력
저하에 대해 "대화 내용을 생각하지 못하고 듣고만 있어요", "텔레 비전을 멍하니 쳐다보고 있어요”라고 언급하였다. 또한 “뉴스를 보 지 않고 노래가 나오는 채널만 봐요”라고 보고하면서 텔레비전 내 용을 이해하지 못하여 회피하는 모습이 확인되었다.

(a) "지난번에 안과에 갔는데 백내장 수술을 해야 된대요. 근데 그걸 이해하지 못하고 원하는 대로 해석하더라고요.", "대화 도 그냥듣고만 있고 생각을 잘 안 하는 것 같아."

(b) "잘 안 봐요. 노래 나오는 거 이런 거 그냥 헤 하면서 보고 있 어. 뉴스라든가 이런 거 코로나 이런 거 이해를 잘 못해요.", "이해를 못 해서 그런지 요즘에는 잘 안 봐요. 드라마 같은 걸 안 보고 스포츠 아니면."

단어

환자들은 단어를 이해하는 데에도 어려움이 있었다. 보호자들 은 '의미적 지식의 손상으로 생긴 이해 결함(a)'과 '단어 표상의 손 상으로 인해 생긴 이해 결함(b)'을 모두 보고하였다.

(a) “약도 그렇고.. 안약.. 평상시에 계속 쓰는데 한 보름 정도는 안 썼단 말이에요. 그럼 이걸 어디에 쓰는 거냐고 하고. 써도 되는 거냐고 하고 다른 것도 또 많이 그러는 게 있어요. 오랜만에 보 는 게 있으면 그게 뭔지를 어디에 쓰는 건지를 모를 때가 많아 요. 사용도를 몰라요."

(b) "조금 이상했던 거는 텔레비전을 보는데 탈춤 할 때 나오는 탈 있죠? 그 탈을 이해를 못 하더라고요. 그래서 '어 이상하다. 왜 탈이라는 말을 이해하지 못할까?’ 그런 적은 있어요.”

말

세 번째로 많이 보고된 언어 문제는 '말' 문제로서, 하위 주제는 '조음, ‘음량', '말속도', ‘말더듬’이 도출되었다.

조음

가장 많이 보고한 문제는 '조음'이었다. 조음 문제에 대해 말이 "어눌해요”, “어둔해요”, “부정확해요”라고 하였는데, 이는 ‘왜곡' 오류를 의미한다.

(a) "발음이 일단 나쁘고 어눌하고 발음이 부정확한 게 제일 커 요. 속도가 느리면서 발음이 엄청 부정확한 거." "안에서만 울리는 거 같아요. 소리가." 
말속도

두 번째로 많이 언급된 문제는 ‘말속도'와 관련된 문제로서, “말 속도가 느려졌어요”라고 보고하였다. 말속도가 느려졌다고 보고된 5 명 중 3명의 환자가 ‘말더듬' 문제를 동반하고 있어, 보호자들이 보고한 말속도 감소는 말더듬과 관련이 있음이 시사되었다.

(a) "말하는 속도가 느려졌어요. 평소에는 느려졌는데. 오늘 은 본인 성질나니까 막 버럭하고 바로 이렇게 나오는데. 그 리고 말을 더듬더듬 말해요."

말더듬

세 번째로 많이 보고된 문제는 ‘말더듬’이었다. 보호자들이 언급 한 ‘말더듬'은 일반적으로 유창성장애로서 '불수의적인 말소리의 반복, 연장, 막힘'이 아닌, ‘말의 심이 많고 더듬더듬하는 말'을 의미 하였다. 또한, 환자의 비유창한 말이 단어 인출의 어려움으로 인한 것이라고 생각하였다.

(a) "말을 더듬기도 하는데. 그게 자기가 잘 생각이 안 나니까 대화를 하는 중에 더듬더듬 이렇게 되는 거지."

음량

음량 변화는 모두 음량 감소와 관련된 것으로서 “목소리가 작아 졌어요”라고보고하였다.

(a) "말하는 속도가많이 느려졌어요. 발음도 좀어눌해지고부 정확하고.목소리도 많이 작아졌어.좀사람이 멍해지고.”

문어표현

'문어 표현'과 관련된 하위 주제는 중추형인 '언어적 측면'의 문제 와 말초형인 '운동적 측면’의 문제로 도출되었다.

언어적 측면

가장 많이 언급된 문제는 언어적인 문제로서, "단어를 쓸 때 뒤 에 이어지는 자소를 생각하지 못하는 것 같아요(a)"라고 하였다. 그 밖에도 “맞춤법을 틀려요(b)", "오타가 심한 문자를 보내요(c)" 등 을 언급하였다.

(a) "글자를 횡설수설하는. 다음에 무슨 글자가 와야 할지를 한참 생각하셔야 한대요."

(b) "맞춤법은 잘 쓰셨는데 요즘은 많이 틀려요. '고맙다 우리
맞딸’이라고 해서 충격받았었어요. 그다음부터는 ‘우리 첫 째 딸'이라고 바꿔 써요. 그거를 막내한테도 그런 거 같아 요. 막내를 소리 나는 대로 ‘망내’라고 해서 우리가 전부 다 나온 적이 있었거든요."

(c) "오타가 심한 문자를 보내요. 그래서 이제는 안 해요. 최근 에는 한 적이 없고."

운동적 측면

운동적인 문제로 인한 쓰기의 어려움도 확인되었다. 가장 많이 보 고한 문제는 글씨체 변화로서, “글씨를 흘려 써요”라고 보고하였다.

(a) '글씨를 예를 들어서 'ㄴ'이면 이렇게 써야 하는데 'ㄱ' 이렇게 쓰고, ‘’이면 이렇게 돼야 하는데 '’' 비슷하게 쓰고. 예전에 는 글씨를 아주 잘 쓰고 정확하게 썼지. 요즘에는 그게 아주 심해요."

계산

계산은 '사칙연산'과 ‘돈 계산’ 두 가지 하위 주제로 도출되었다.

돈계산

보호자들은 환자들이 돈 계산을 하는 데 어려움이 있다고 보고 하면서, 이로 인해 돈 관리를 맡기기 불안하다고 하였다.

(a) "계산능력은 떨어진 거 같아요. 돈이라든지. 이런 게 잘 이해가 안 되고. 천 원 이천 원 이런 거 더하기 숫자 이런 거 잘 안돼요.", “중요한 돈 관리를 맡기기는 불안해요."

사칙연산

진행성 실어증 환자들은 비교적 쉬운 계산인 '사칙연산'에서도 어려움을 보였다.

(a) "사칙연산 같은 거는.. 사칙연산도 좀 떨어져요."

\section{문어 이해}

문어를 이해하는 데 어려움이 있다고 보고하였는데, '독해' 하나 의 하위 주제가 도출되었다.

\section{독해}

보호자들은 환자들이 “읽으려고 하지 않아요(a)"라고 호소하며 읽기 상황을 회피한다고 하였고, '읽기는 가능하지만 이해하지는 
못해요(b)", "복잡한 글을 이해하지 못하는 것 같아요(c)"라고 보고 하였다.

(a) "그냥 핸드폰 문자가 오면 직접 보여주지 뭐. 이거에 대해 그냥 물어보지. 헷갈리는 것 같진 않고 그냥 모르시니까. 생각 안 하 고 그냥 물어보는 거. 해야 될 거를. '니가 해라' 그냥 줘버려요."

(b) "글을 읽긴 하는데 무슨 말인지 잘 몰라요. 이건 매우 그렇다 고 봐야 돼."

(c) "복잡한 글도 이해 못 해 신문 같은 거."

\section{언어장애 증상 정도}

중위수 ‘4점(그렇다)' 이상인 문항을 확인한 결과, '구어 표현' 측 면에서 '단어가 얼른 떠오르지 않는 것 같다', '하려는 말이 바로 나 오지 않고 입안에서 맴도는 것 같다', '떠오른 단어가 말로 잘 나오 지 않는 것 같다', '사용하는 어휘 양이 줄어들었다' 문항 점수가 높 게 나타나, 환자들이 단어 인출에서 어려움이 두드러진 것을 확인 할 수 있었다. 그 밖에도 '발화 수 감소'와 ‘주제 폭 감소' '주제 이탈' 문제가 심한 것으로 나타났다. '구어 이해' 측면에서는 '말을 이해하 지 못하고 되묻는다', '텔레비전을 볼 때 내용을 잘 이해하지 못하 는 것 같다', '대화 내용을 잘 이해하지 못하는 것 같다' 문항 점수가 높게 나타났다. 이는 환자들이 단어에 비해 문장 및 담화를 이해하 는 데 어려움이 있음을 시사한다. '문어 이해'에서는 '복잡한 글을 잘 이해하지 못하는 것 같다' 문항의 중위수가 가장 높게 나타났으 며, ‘말’ 측면에서는 말 속도 저하가 가장 두드러진 문제였다.

\section{논의 및 결론}

보호자가 보고하는 환자의 주호소는 치료를 요구하는 이유뿐만 아니라 의료진이 환자를 분류하는 의사 결정과 관련된 많은 정보 를 담고 있다(Mowafi et al., 2013). 실제로 의료기관 방문 시에 보호 자는 의료진과의 면담을 통하여 환자의 상태를 보고하게 되고, 의 료진은 이러한 병력 청취 상의 주호소에 근거하여 진단을 내리고 적절한 치료법을 제시하게 된다. 그러나 보호자는 동일한 증상에 대해서도 각기 다른 표현을 사용하여 증상을 설명하게 되는데, 환 자의 문제점을 정확하게 인지하지 못하거나, 인지한다고 하더라도 그 보고가 체계적이지 못하다. 따라서 환자에게 관찰되는 주 증상 또는 주호소를 의료진이 짧은 시간 내에 정확하게 확인하기 위해 서, 전문가의 개입에 의한 반구조화된 인터뷰를 통한 설문 평가가 필요하다.

본 연구에서는 주제 분석을 통하여 진행성 실어증 환자의 언어
장애 증상을 확인하고, 각 주제의 빈도를 도출하여 진행성 실어증 환자들에게 빈번하게 나타나는 언어 문제를 밝혔다. 또한, 환자가 보이는 언어장애 증상 정도, 즉 환자들에게 가장 심하게 나타나는 문제를 확인하였다. 주제 분석을 통해 밝혀진 결과와 그에 따른 논 의는 다음과 같다. 보호자 인터뷰 주제 분석 결과, 도출된 상위 주 제는 '구어 표현, '구어 이해', '문어 표현', '문어 이해', '계산', '말'이 었다. 가장 많이 보고된 언어 문제는 '구어 표현'에서의 어려움이었 으며, '구어 표현'의 하위 주제 중 단어 인출 문제가 가장 많이 언급 되었다. 반구조화된 인터뷰를 통하여 단어 인출의 어려움으로 인 해 나타난 문제와 더불어, 단어 인출 문제가 있을 때 환자들이 사용 하는 전략을 확인할 수 있었다. 환자들은 단어를 말해야 하는 상황 을 피하는 '회피' 전략을 사용하였으며, 단어를 에둘러서 표현하는 '에둘러말하기' 전략을 구사하였다. 또한 “더 큰 범주로 말하고 점 점 좁혀가면서 단어를 말하려고 한다"고 함으로써, 특정 범주에 속 한 단어를 산출하지 못하는 '단어 인출' 결함으로 인하여 '상위 범 주로 말하기'를 사용하는 것으로 나타났다. 실어증 환자들은 단어 인출 결함을 해결하기 위하여 자기단서전략(self-cueing strategies) 을 사용한다(Hwang, Woo, \& Kim, 2015). 진행성 실어증을 동반한 인지 저하 환자들의 단어 인출 전략 효과를 살펴본 연구는 없으나, ‘에둘러말하기'나 '상위 범주로 말하기'가 전략의 예가 될 수 있다. 한편, 반향어를 보인 환자의 경우, 초진 기록에 의하면 "질문과 다 른 대답을 한다"고 보고된 바 있는데, 이후 1-2년 경과 후 추적 검사 시에는 상대방의 말을 따라 하는 특색이 확인되었다. 이러한 현상 에 비추어 볼 때, 상대방의 말을 따라 하는 특성은 이해력 저하와 관련이 있을 수 있으며, 중증도가 심한 환자에게 나타나는 특성임 을 확인할수 있었다.

두 번째로 많이 언급된 상위 주제는 ‘구어 이해’이며, 하위 주제 는 '단어', '문장', '담화'이었다. '단어' 이해 상의 문제는 두 가지 유 형으로 분류되는데, 하나는 의미적 지식(semantic knowledge)의 손상에 기인하고, 다른 하나는 의미적 지식은 보존되어 있지만 의 미적 지식과 단어의 음운적 표상이 단절되어 생긴 문제이다(Antonucci, Beeson, Labiner, \& Rapcsak, 2008). 예를 들어, 물건의 쓰임 자체를 이해하지 못하는 경우에는 의미적 지식의 손상으로 인해 이해 결함이 나타나는 것이라고 할 수 있다. 반면에 물건의 쓰임은 알고 있지만 단어를 들었을 때 이해하지 못하는 것은 의미적 지식 과 음운적 표상의 단절로 인하여 이해 결함이 나타난 것으로 볼수 있다.

본 연구의 환자들은 단어에 비해 문장 및 담화 이해에서 어려움 을 더 많이 보고하였다. 문장을 이해하기 위해서 통사적 처리 능력 과 구어 작업기억(verbal working memory) 능력이 요구된다 
(Kempler, Almor, Tyler, Andersen, \& MacDonald, 1998). 즉, 문장 및 담화를 이해하기 위해서는 단어를 처리할 때보다 더 많은 인지언어적 처리 능력이 필요하다. 진행성 실어증 환자들은 작업기억 등을 포함한 인지기능의 저하로 인해 문장이나 담화를 처리하는 데 부정적인 영향을 받는다(Welland, Lubinski, \& Higginbotham, 2002).

세 번째로 많이 언급된 상위 주제는 ‘말’이었다. '말' 문제 중 가장 많이 언급된 '조음' 오류는 언어 표현 및 이해 문제에 비해 비교적 나중에 나타난다고 보고된 바 있지만(Müller \& Guendouzi, 2005), '어눌한 말'은 치매 초기부터 나타나거나(Lee \& Kim, 2019), 진행성 실어증 유형(예, nfvPPA)에 따라 주요 증상이 될 수 있다. 이 연구에 서 '어눌한 말'이 보고된 바, 실제로 환자들이 이 증상을 보고한 시 기와 어떤 유형의 환자인지를 상세히 확인할 필요가 있다.

문어 표현 측면에서 “문자를 보낼 때 오타가 나요", "이전과 다르 게 문자를 보내지 못해요”라고 하였는데, 디지털 기기의 사용이 증 가하면서 이러한 문제점이 잘 관찰될 수 있다. '문자' 사용상의 어려 움은 비단 언어적인 측면뿐만 아니라, 감각적인 그리고 운동적인 측 면에 기인한다(An \& Park, 2019; Chen, Chan, \& Tsang, 2013). 즉, 철 자 오류라는 결과적인 문제는 잘못된 자소(grapheme)의 선택에 따 를 수 있고, 시각 저하로 인하여 휴대폰의 작은 자판을 잘 인식하지 못하거나, 손가락 운동 기능의 저하로 자판을 잘 못 누를 수 있다.

문어를 이해하는 데에도 어려움이 있었다. 특히 독해 능력의 저 하는 다양한 유형의 치매 환자들에게 나타나는 언어 증상인데, svPPA 환자들은 발병 초기부터 독해 문제가 나타난다(Coltheart, Tree, \& Saunders, 2010).

계산 능력의 저하는 $\mathrm{AD}$, 경도인지장애(mild cognitive impairment, $\mathrm{MCI}$ ) 등을 포함한 다양한 유형의 인지 저하 환자들에게 빈 번하게 나타나는 증상이다(Marterer, Danielczyk, Simanyi, \& Fischer, 1996; Sherod et al., 2009). 많은 선행연구에서 계산능력을 평 가하기 위하여 오류율 및 오류 유형만을 보고하였으나(Kim, Kim, Yoon, \& Cho, 2017; Marterer et al., 1996), 본 연구의 환자들은 계 산 시 지연된 반응을 보고하였다. “계산을 틀리지는 않지만 계산하 는 데 시간이 오래 걸린다"는 지연 현상이 인지 저하를 예측하는 요 인일 수 있다.

본 연구는 환자의 언어 증상 정도를 확인하기 위해 EMR에서 보 고된 주호소 조사를 통하여 언어 설문지를 제작한 후, 보호자들에 게 현재 환자의 언어능력에 대해 Likert 5 점 척도로 응답하게 하였 다. 증상의 정도는 삶의 질과 밀접한 관련이 있다는 점에서, 본 연구 를 통해 밝혀진 진행성 실어증 환자들이 가장 어려움을 보이는 언 어 증상을 확인하고 중재 계획을 수립해야 할 것이다.
본 연구의 의의는 다음과 같다.

첫째, 뇌졸중과 같은 병인으로 발생하는 비진행성 실어증에 대 한 연구는 활발히 이루어져 왔지만, 진행성 실어증에 대한 연구는 미비하였다. 이로 인해 진행성 실어증에 대한 이해가 부족하며, 진 행성 실어증을 동반하는 환자들에게 적절한 중재를 제공하는 데 어려움이 있어왔다. 본 연구는 보호자 주호소를 분석하여 진행성 실어증의 언어능력을 이해하는 데 도움을 줄 수 있을 것이다.

둘째, 보호자가 보고하는 주호소를 분석하는 것이 환자의 증상 을 파악하는 데 유용하지만, 보호자들이 환자의 언어 문제를 정확 하게 인식하지 못하거나, 언어 증상을 인지 증상과 혼동하는 경우 역시 많았다. 본 연구를 통해 연구자의 주도에 의한 반구조화된 인 터뷰를 진행하면서 모호한 응답에 대해 자세히 설명해 줄 것을 요 구하거나, 말을 수정하여 되물어 보면서 보호자가 보고하는 환자 의 언어 문제를 정확하게 파악할 수 있었다.

본 연구의 한계점과 후속 연구를 위한 제언은 다음과 같다.

첫째, 본 연구에서는 진행성 실어증의 언어 특성을 파악하고, 진 행성 실어증 환자 진단에 활용할 수 있는 '언어 설문지'를 개발하였 다. 그러나 설문지의 타당도 및 신뢰도가 검증되지 않았으므로 이 에 대한 후속 연구의 필요성이 제기된다.

둘째, 본 연구에서는 대면 인터뷰를 통한 자료 수집을 진행하였 으나, 코로나바이러스감염증-19 (COVID-19)로 인하여 대상자 모 집에 한계가 있었으므로 표본 수가 적었다. 따라서 후속 연구에서 는 진행성 실어증 유형별로 분류되어 분석할 수 있는 충분한 표본 수를 확보하여 유형별 주호소가 다를지 여부를 판단하는 것이 바 람직할 것이다.

요약컨대, 본 연구는 보호자 주호소를 분석하여 진행성 실어증 환자의 언어능력을 파악하고, 이를 근거로 하여 진행성 실어증 환 자의 언어능력을 평가하기 위한 '언어 설문지'의 기틀을 마련하였 다. 후속 연구에서는 설문지의 타당도 및 신뢰도 검증을 통하여, 설 문지가 임상에서 진행성 실어증 환자의 언어능력을 평가하는 데 활 용될 수 있기를 기대한다.

\section{REFERENCES}

Antonucci, S. M., Beeson, P. M., Labiner, D. M., \& Rapcsak, S. Z. (2008). Lexical retrieval and semantic knowledge in patients with left inferior temporal lobe lesions. Aphasiology, 22(3), 281-304.

An, J. W., \& Park, K. O. (2019). Smartphone utilization and satisfaction in community dwelling elderly. Journal of the Korean Society of Living Environment System, 26(4), 540-549. 
Chen, A. H., Bakar, N. A., \& Lam, C. S. (2020). Comparison of open-ended and close-ended questions to determine signs and symptoms of eye problems among children. Journal of Optometry, 13(2), 81-87.

Chen, K., Chan, A. H., \& Tsang, S. N. (2013). Usage of mobile phones amongst elderly people in Hong Kong. In Proceedings of the International MultiConference of Engineers and Computer Scientists (Vol. 2).

Croot, K., Raiser, T., Taylor-Rubin, C., Ruggero, L., Ackl, N., Wlasich, E., ..., \& Nickels, L. (2019). Lexical retrieval treatment in primary progressive aphasia: an investigation of treatment duration in a heterogeneous case series. Cortex, 115, 133-158.

Coltheart, M., Tree, J. J., \& Saunders, S. J. (2010). Computational modeling of reading in semantic dementia: comment on Woollams, Lambon Ralph, Plaut, and Patterson (2007). Psychological Review, 117(1), 256-272.

Gorno-Tempini, M. L., Dronkers, N. F., Rankin, K. P., Ogar, J. M., Phengrasamy, L., Rosen, H. J., ..., \& Miller, B. L. (2004). Cognition and anatomy in three variants of primary progressive aphasia. Annals of Neurology, 55(3), 335-346.

Gorno-Tempini, M. L., Hillis, A. E., Weintraub, S., Kertesz, A., Mendez, M., Cappa, S. F., ..., \& Grossman, M. (2011). Classification of primary progressive aphasia and its variants. Neurology, 76(11), 1006-1014.

Hilari, K., \& Byng, S. (2009). Health-related quality of life in people with severe aphasia. International Journal of Language \& Communication Disorders, 44(2), 193-205.

Henry, M. L., Beeson, P. M., \& Rapcsak, S. Z. (2008). Treatment for lexical retrieval in progressive aphasia. Aphasiology, 22(7-8), 826-838.

Harciarek, M., Sitek, E. J., \& Kertesz, A. (2014). The patterns of progression in primary progressive aphasia: implications for assessment and management. Aphasiology, 28(8-9), 964-980.

Hwang, J. H., Woo, H. R., \& Kim, J. W. (2015). Self-cueing strategies of word retrieval by patient with aphasia. Proceedings of conference on the Korean Academy of Speech-Language and Hearing Association, 222-223.

Johnson, M., \& Lin, F. (2014). Communication difficulty and relevant interventions in mild cognitive impairment: Implications for neuroplasticity. Topics in Geriatric Rehabilitation, 30(1), 18-34.

Jones, L., \& Tanner, T. (2015). Measuring subjective resilience: using people's perceptions to quantify household resilience. Working Paper 423. Overseas Development Institute, London, UK.

Kang, Y., Na, D. L., \& Hahn, S. H. (1997). A validity study on the Korean Mini-Mental State Examination (K-MMSE) in dementia patients. Journal of the Korean Neurological Association, 15(2), 300-308.
Kempler, D., Almor, A., Tyler, L. K., Andersen, E. S., \& MacDonald, M. C. (1998). Sentence comprehension deficits in Alzheimer's disease: a comparison of off-line vs. on-line sentence processing. Brain and Language, 64(3), 297-316.

Kim, S., Kim, H., Nam, S. I., \& Kim, H. S. (2020). A thematic analysis of speech self-awareness in the community-dwelling elderly. Communication Sciences \& Disorders, 25(1), 156-168.

Kim, J. Y., Kim, H., Yoon, J. H., \& Cho, S. R. (2017). Numerical processing and calculation deficits in Alzheimer's disease. Communication Sciences \& Disorders, 22(1), 138-145.

Kim, H., \& Na, D. L. (1997). Korean-Boston Naming Test. Seoul: Hakji Co.

Klimova, B., Maresova, P., Valis, M., Hort, J., \& Kuca, K. (2015). Alzheimer's disease and language impairments: social intervention and medical treatment. Clinical Interventions In Aging, 10, 1401-1407.

Lee, S. S., \& Kim, M. J. (2019). Diagnosis and clinical progress in a case of dementia with Lewy bodies. Journal of the Korean Society of Biological Therapies in Psychiatry, 25(1), 60-68.

Mesulam, M. (1990). Essentials of primary progressive aphasia. Turkish Journal of Neurology, 13(1), 52-67.

Mowafi, H., Dworkis, D., Bisanzo, M., Hansoti, B., Seidenberg, P., Obermeyer, Z., ..., \& Reynolds, T. A. (2013). Making recording and analysis of chief complaint a priority for global emergency care research in low-income countries. Academic Emergency Medicine: Official Journal of the Society for Academic Emergency Medicine, 20(12), 1241-1245.

Marterer, A., Danielczyk, W., Simanyi, M., \& Fischer, P. (1996). Calculation abilities in dementia of Alzheimer's type and in vascular dementia. Archives of Gerontology and Geriatrics, 23(2), 189-197.

Müller, N., \& Guendouzi, J. A. (2005). Order and disorder in conversation: encounters with dementia of the Alzheimer's type. Clinical Linguistics \& Phonetics, 19(5), 393-404.

Nowell, L. S., Norris, J. M., White, D. E., \& Moules, N. J. (2017). Thematic analysis: striving to meet the trustworthiness criteria. International Journal of Qualitative Methods, 16(1), 1-13.

Nuvoli, S., Tanda, G., Stazza, M. L., Madeddu, G., \& Spanu, A. (2019). Qualitative and quantitative analyses of brain 18fluoro-deoxy-glucose positron emission tomography in primary progressive aphasia. Dementia and Geriatric Cognitive Disorders, 48(5-6), 250-260.

Olney, N. T., Spina, S., \& Miller, B. L. (2017). Frontotemporal dementia. Neurologic Clinics, 35(2), 339-374.

Petrova, M., Pavlova, R., Zhelev, Y., Mehrabian, S., Raycheva, M., \& Traykov, 
Ka young Kim, et al. - Caregivers' Communication Chief Complaints in Progressive Aphasia

L. (2016). Investigation of neuropsychological characteristics of very mild and mild dementia with Lewy bodies. Journal of Clinical and Experimental Neuropsychology, 38(3), 354-360.

Sherod, M. G., Griffith, H. R., Copeland, J., Belue, K., Krzywanski, S., Zamrini, E. Y., ..., \& Marson, D. C. (2009). Neurocognitive predictors of financial capacity across the dementia spectrum: normal aging, mild cognitive impairment, and Alzheimer's disease. Journal of the International Neuropsychological Society, 15(2), 258-267.
Wang, Y., Shang, P., Xin, M., Bai, J., Zhou, C., \& Zhang, H. L. (2017). The usefulness of chief complaints to predict severity, ventilator dependence, treatment option, and short-term outcome of patients with Guillain-Barré syndrome: a retrospective study. BMC Neurology, 17(1), 1-8.

Welland, R. J., Lubinski, R., \& Higginbotham, D. J. (2002). Discourse comprehension test performance of elders with dementia of the Alzheimer type. Journal of Speech, Language, and Hearing Research, 45(6), 1175-1187. 
Appendix 1. Questionnaire for caregiver interview

\begin{tabular}{|c|l|l|l|}
\hline 환자명 & 성별/나이 & 남, 여 / 만 세 \\
\hline 연구일련번호 & 설문 날짜 & \\
\hline
\end{tabular}

본 설문지를 통해 환자분의 언어능력을 평가하고자 합니다. 각 문항을 읽으시고 1점(전혀 아니다) 5점(매우 그렇다) 중 해당한다고 생각하는 점수에 동그라미(O) 해주세요.

이전과 비교한 현재 환자의 ‘구어 표현’에 대해 점수를 매겨주세요.

\begin{tabular}{|c|c|c|c|c|c|c|c|}
\hline No. & 문항 & $\begin{array}{c}\text { 전혀 그렇지 } \\
\text { 않다 }\end{array}$ & $\begin{array}{l}\text { 그렇지 } \\
\text { 않다 }\end{array}$ & 보통이다 & 그렇다 & $\begin{array}{l}\text { 매우 } \\
\text { 그렇다 }\end{array}$ & 비고 \\
\hline 1 & 단어(사물, 사람 이름, 지명 등)가 얼른 떠오르지 않는 것 같다. & 1 & 2 & 3 & 4 & 5 & \\
\hline 2 & 하려는 말이 바로 나오지 않고 입안에서 맴도는 것 같다. & 1 & 2 & 3 & 4 & 5 & \\
\hline 3 & 떠오른 단어가 말로 잘 나오지 않는 것 같다. & 1 & 2 & 3 & 4 & 5 & \\
\hline 4 & 단어를 헷갈리는 것 같아 보인다. & 1 & 2 & 3 & 4 & 5 & \\
\hline 5 & 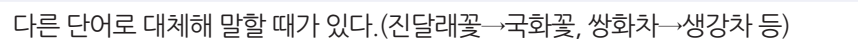 & 1 & 2 & 3 & 4 & 5 & \\
\hline 6 & 상황에 적합한 단어를 잘 찾지 못하고, 뭉뚱그려 사용할 수 있는 단어를 사용한다. & 1 & 2 & 3 & 4 & 5 & \\
\hline 7 & 대용어('아’ ‘그', ‘저’ 등)를 많이 사용한다. & 1 & 2 & 3 & 4 & 5 & \\
\hline 8 & 사용하는 어휘 양이 줄어들었다. & 1 & 2 & 3 & 4 & 5 & \\
\hline 9 & 대화 주제의 폭이 좁아졌다. & 1 & 2 & 3 & 4 & 5 & \\
\hline 10 & 대화 중 주제에 벗어난 말을 한다. & 1 & 2 & 3 & 4 & 5 & \\
\hline 11 & 이야기의 일부분만 하는 경우가 많다. & 1 & 2 & 3 & 4 & 5 & \\
\hline 12 & 맥락 없이 본인이 하고 싶은 말만 한다. & 1 & 2 & 3 & 4 & 5 & \\
\hline 13 & 말을 횡설수설하는 모습을 보인다. & 1 & 2 & 3 & 4 & 5 & \\
\hline 14 & 헛소리를 많이 한다. & 1 & 2 & 3 & 4 & 5 & \\
\hline 15 & 문장의 앞뒤가 맞지 않는 말을 한다. & 1 & 2 & 3 & 4 & 5 & \\
\hline 16 & 조리 있게 문장을 구성하지 못한다. & 1 & 2 & 3 & 4 & 5 & \\
\hline 17 & 이야기를 할 때 삼천포로 빠진다. & 1 & 2 & 3 & 4 & 5 & \\
\hline 18 & 말 길이가 짧아졌다. & 1 & 2 & 3 & 4 & 5 & \\
\hline 19 & 말 수가 눈에 띄게 줄어들었다. & 1 & 2 & 3 & 4 & 5 & \\
\hline 20 & 자발적으로 말을 시작하는 경우가 거의 없다. & 1 & 2 & 3 & 4 & 5 & \\
\hline 21 & 상대방의 말을 따라 한다. & 1 & 2 & 3 & 4 & 5 & \\
\hline 22 & 감정 표현이 줄었다. & 1 & 2 & 3 & 4 & 5 & \\
\hline
\end{tabular}

이전과 비교한 현재 환자의 ‘구어 이해’에 대해 점수를 매겨주세요.

\begin{tabular}{|c|c|c|c|c|c|c|c|}
\hline No. & 문항 & $\begin{array}{l}\text { 전혀 그렇지 } \\
\text { 않다 }\end{array}$ & $\begin{array}{l}\text { 그렇지 } \\
\text { 않다 }\end{array}$ & 보통이다 & 그렇다 & $\begin{array}{c}\text { 매우 } \\
\text { 그렇다 }\end{array}$ & 비고 \\
\hline 1 & 물건의 이름을 잘 이해하지 못하고, 처음 듣는 것처럼 행동한다. & 1 & 2 & 3 & 4 & 5 & \\
\hline 2 & 물건의 쓰임을 이해하지 못한다. & 1 & 2 & 3 & 4 & 5 & \\
\hline 3 & 질문과 다른 대답을 한다. & 1 & 2 & 3 & 4 & 5 & \\
\hline 4 & 엉뚱하게 대답할 때가 있다. & 1 & 2 & 3 & 4 & 5 & \\
\hline 5 & 말을 이해하는 속도가 느려진 것 같다. & 1 & 2 & 3 & 4 & 5 & \\
\hline 6 & 말을 이해하지 못하고 되묻는다. & 1 & 2 & 3 & 4 & 5 & \\
\hline 7 & 질문에 답을 늦게 한다. & 1 & 2 & 3 & 4 & 5 & \\
\hline 8 & 텔레비전을 볼 때 내용을 잘 이해하지 못하는 것 같다. & 1 & 2 & 3 & 4 & 5 & \\
\hline 9 & 대화 내용을 잘 이해하지 못하는 것 같다. & 1 & 2 & 3 & 4 & 5 & \\
\hline
\end{tabular}


Appendix 1. Continued

이전과 비교한 현재 환자의 ‘문어 표현’에 대해 점수를 매겨주세요.

\begin{tabular}{|c|c|c|c|c|c|c|c|}
\hline No. & 문항 & $\begin{array}{c}\text { 전혀 그렇지 } \\
\text { 않다 }\end{array}$ & 그렇지 않다 & 보통이다 & 그렇다 & 매우 그렇다 & 비고 \\
\hline 1 & 글씨체가 변한 것 같다.(예, 글씨를 흘려 쓴다) & 1 & 2 & 3 & 4 & 5 & \\
\hline 2 & 맞춤법을 틀린다. & 1 & 2 & 3 & 4 & 5 & \\
\hline 3 & 오타가 심한 문자를 보낸다. & 1 & 2 & 3 & 4 & 5 & \\
\hline
\end{tabular}

이전과 비교한 현재 환자의 ‘문어 이해’에 대해 점수를 매겨주세요.

\begin{tabular}{|c|c|c|c|c|c|c|c|}
\hline No. & 문항 & $\begin{array}{l}\text { 전혀 그렇지 } \\
\text { 않다 }\end{array}$ & 그렇지 않다 & 보통이다 & 그렇다 & 매우 그렇다 & 비고 \\
\hline 1 & 읽기는 가능하지만 내용을 이해하지 못한다. & 1 & 2 & 3 & 4 & 5 & \\
\hline 2 & 복잡한 글을 이해하지 못하는 것 같다.(예, 신문, 광고 등) & 1 & 2 & 3 & 4 & 5 & \\
\hline 3 & 글자를 빠뜨리고 읽을 때가 있다. & 1 & 2 & 3 & 4 & 5 & \\
\hline
\end{tabular}

이전과 비교한 현재 환자의 ‘계산에 대해 점수를 매겨주세요.

\begin{tabular}{|c|c|c|c|c|c|c|c|}
\hline No. & 문항 & $\begin{array}{l}\text { 전혀 그렇지 } \\
\text { 않다 }\end{array}$ & 그렇지 않다 & 보통이다 & 그렇다 & 매우 그렇다 & 비고 \\
\hline 1 & 계산하는 데 시간이 오래 걸린다.(예, 돈 계산) & 1 & 2 & 3 & 4 & 5 & \\
\hline
\end{tabular}

이전과 비교한 현재 환자의 '말'에 대해 점수를 매겨주세요.

\begin{tabular}{|c|c|c|c|c|c|c|c|}
\hline No. & 문항 & $\begin{array}{c}\text { 전혀 그렇지 } \\
\text { 않다 }\end{array}$ & 그렇지 않다 & 보통이다 & 그렇다 & 매우 그렇다 & 비고 \\
\hline 1 & 말하는 속도가 느려졌다. & 1 & 2 & 3 & 4 & 5 & \\
\hline 2 & 목소리가 잘 나오지 않는 것 같다. & 1 & 2 & 3 & 4 & 5 & \\
\hline 3 & 쉰 목소리가 난다. & 1 & 2 & 3 & 4 & 5 & \\
\hline 4 & 발음이 어눌해졌다. & 1 & 2 & 3 & 4 & 5 & \\
\hline 5 & 발음이 부정확해졌다. & 1 & 2 & 3 & 4 & 5 & \\
\hline 6 & 목소리가 작아졌다. & 1 & 2 & 3 & 4 & 5 & \\
\hline 7 & 말을 더듬는다. & 1 & 2 & 3 & 4 & 5 & \\
\hline
\end{tabular}




\section{국문초록}

\section{진행성 실어증 환자의 보호자 보고에 의한 의사소통 관련 주호소의 주제 및 빈도 분석}

김가영 1 예병석 $\cdot$ 이주희 ${ }^{3}$ 김향희 ${ }^{14}$

${ }^{1}$ 연세대학교 대학원 언어병리학협동과정, ${ }^{2}$ 연세대학교 의과대학 신경과학교실, ${ }^{3}$ 연세대학교 간호대학 간호학과, ${ }^{4}$ 연세대학교 의과대학 재활의학교실 및 재활의학연구소

배경 및 목적: 진행성 실어증은 서서히 나타나는 증상으로서, 환자의 의사소통 능력 변화를 가장 빨리 인식할 수 있는 사람은 환자의 보호자이다. 환자에게 적절한 중재를 제공하기 위해서 보호자 주호소를 분석할 필요가 있다. 방법: 제 1 단계에서 진행성 실어증 환자 44 명(남:여 $=19: 25$, 평균 연령 $=70.5 \pm 10.14$ )의 전자의무기록(EMRs)을 활용하여 언어 관련 주호소를 정리하고, NVivo 1.0 을 사용하여 주제 분석하였으며, 이를 바탕으로 45 개 문항의 언어 설문지가 개발되었다. 제 2 단계에서 개발된 언어 설문지를 활용하여 보호자 9명 (남:여 =2:7. 평균 연령 $=56.5 \pm 12.82$ )에게 반구조화된 인터뷰를 실시하였으며, 인터뷰 내용을 주제 및 빈도 분석하였다. 결과: 주제 분 석 결과, 총 6 개의 상위 주제와 총 18 개의 하위 주제가 도출되었다. 상위 주제는 '구어 표현', '구어 이해', '문어 표현', '문어 이해', '계산', '말'이 포함되었다. 각 상위 주제에서 가장 빈번하게 도출된 하위 주제는 '단어, '문장', '언어적 측면', '독해', '돈 계산, '조음이었다. 더불 어, 보호자들이 가장 심하다고 느끼는 환자의 언어 문제는 '구어 표현', '구어 이해’ '문어 이해', '말’이었다. 논의 및 결론: 주호소는 진행 성 실어증 환자의 현재 의사소통 능력을 반영하는 주요한 정보이다. 따라서 본 연구의 결과는 임상가들과 환자/보호자들이 진행성 실 어증에서 보이는 의사소통장애의 본질을 제대로 이해하고, 치료 계획을 수립하는 데 도움을 줄수 있을 것이다.

핵심어: 진행성 실어증, 치매, 의사소통 관련 주호소, 주제 분석, 빈도 분석, 보호자 설문지

본 논문은 제 1 저자의 연세대학교 석사학위논문을 발췌 및 수정한 것임.

본 논문은 2017년 대한민국 교육부와 한국연구재단의 지원을 받아수행된 연구임(No. NRF-2017S1A5A2A01025920).

\section{참고문헌}

강연욱, 나덕렬, 한승혜. (1997). 치매환자들을 대상으로 한 K-MMSE의 타당도 연구. 대한신경과학회지, 15(2), 300-308.

김수민, 김향희, 남석인, 김한샘 (2020). 지역사회 거주 노인의 말 자가인식 보고에 대한주제 분석. Communication Sciences \& Disorders, 25(1), 156-

168.

김주연, 김향희, 윤지혜, 조성래 (2017). 알츠하이머성 치매 환자의 숫자 처리 및 계산 특성. Communication Sciences \& Disorders, 22(1), 138-145.

김향희, 나덕렬 (1997). 한국판 보스톤 이름대기 검사. 서울: 학지사.

안지원, 박경옥 (2019). 지역사회 거주 노인의 스마트폰 만족도 및 활용도. 한국생활환경학회지, 26(4), 540-549.

이상신, 김민정 (2019). 루이소체 치매 1례의 진단 및 임상경과. 생물치료정신의학, 25(1), 60-68.

황재호, 우희림, 김정완 (2015). 실어증 환자의 어휘인출 과정에서의 자기단서전략. 한국언어치료학회 학술발표대회 논문집, 222-223.

\section{ORCID}

김가영(제1저자, 대학원생 https://orcid.org/0000-0002-4126-5916); 예병석(공동교신저자, 교수 https://orcid. org/0000-0003-0187-8440); 이주희(공동저자, 교수 https://orcid. org/0000-0002-2805-1622); 김향희(공동교신저자, 교수 https://orcid.org/0000-0003-4949-2512) 